\title{
Maximum entropy decoding of multivariate neural spike trains Hélène Seiler ${ }^{\dagger 1,2}$, Yang Zhang ${ }^{\dagger 1,2}$, Aman B Saleem², Phil Bream², John Apergis-Schoute ${ }^{2}$ and Simon R Schultz*2
}

\author{
Address: ${ }^{1}$ Department of Physics, Imperial College London, London SW7 2AZ, UK and ${ }^{2}$ Department of Bioengineering, Imperial College London, \\ London SW7 2AZ, UK \\ Email: Simon R Schultz* - s.schultz@imperial.ac.uk \\ * Corresponding author †Equal contributors
}

from Eighteenth Annual Computational Neuroscience Meeting: CNS*2009

Berlin, Germany. 18-23 July 2009

Published: 13 July 2009

BMC Neuroscience 2009, I0(Suppl I):PI07 doi:I0.II86/I47I-2202-I0-SI-PI07

This abstract is available from: http://www.biomedcentral.com//47I-2202/I0/SI/PI07

(c) 2009 Seiler et al; licensee BioMed Central Ltd.

Scalable algorithms for decoding the information content of trains of action potentials fired by ensembles of neurons are of increasing interest for several reasons. Firstly, neurophysiological recording approaches such as multielectrode arrays (MEAs) and two-photon calcium imaging are now producing recordings from unprecedented numbers and densities of neurons simultaneously. Secondly, recent work in the area of brain-machine interfaces has opened up the opportunity of taking advantage of such algorithms for purposes such as prosthetic device control, perceptual readout and communication with tetraplegic and "locked-in syndrome" patients. One approach taken for decoding multivariate neural spike trains is Bayesian decoding (see e.g. [1]), where the stimulus $s$ is decoded via the rule $s=\operatorname{argmax}_{\mathrm{s}}\left\{P^{*}(\mathrm{r} \mid s) P(s) / P^{*}(\mathrm{r})\right\}$, where $P^{*}$ refers to a model response probability function fit using a "training" dataset. In the present work, we extend this approach to maximum entropy models of neural population response patterns [2,3]. To preserve decoder temporal resolution, we decode spatial patterns of spikes from time windows short enough that the responses of each cell can be considered binary. We use a training dataset to measure trial-averaged $n^{\text {th }}$ order correlations, then apply a numerical optimization algorithm to compute online the likelihood of observing each response pattern in the test dataset. We have examined the cross-validated performance of the algorithm by decoding patterns of activity in a 2D Ising Model in which stimulus dependent statistical structure has been imposed at different orders (see Figure 1 ). In addition to studying simulated data, we demon-

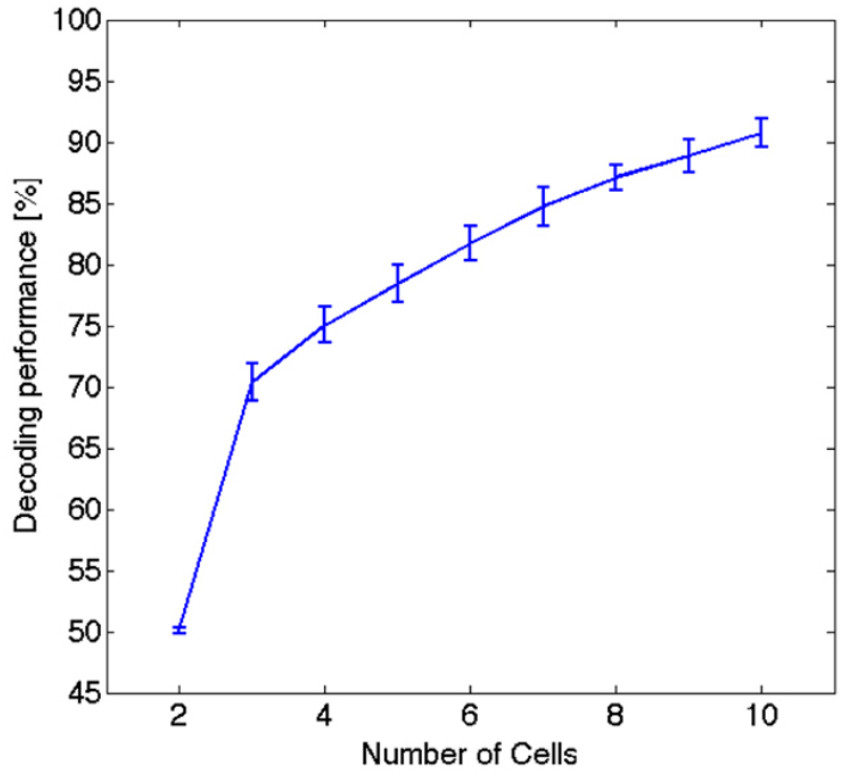

Figure I

Decoding performance for test data comprised of neural ensembles of various sizes. The data come from a 2D Ising model simulation. In this example, stimulus-dependent patterns were imposed via the field term in the Ising model. We have found the $2 \mathrm{D}$ Ising model to be a useful tool for evaluating the performance of multivariate spike train decoding algorithms in different regimes of spatiotemporal response pattern statistics. 
strate the practicality of the technique by applying it to two physiological datasets. In the first dataset, we decode the direction of a drifting grating stimulus from spike trains recorded simultaneously by a MEA in the mouse visual cortex. In the second, we decode the time of occurrence of an air puff stimulus to the lip of a rat, from twophoton fluorescence imaging of complex-spike-related calcium signals in the rodent cerebellum. Our results suggest that the maximum entropy algorithm can be an effective approach for decoding neural ensemble activity when information content is embedded in spatial activity patterns.

\section{Acknowledgements}

This research was supported by EPSRC grant EP/E00233I/I.

\section{References}

I. Oram MW, Foldiak P, Perrett I, Sengpiel : The 'ideal homunculus': decoding neural population signals. Trends Neurosci 1998, 21:259-265.

2. Schneidman E, Berry MJ 2nd, Segev R, Bialek W: Weak pairwise correlations imply strongly correlated network states in a neural population. Nature 2006, 440:1007-1012.

3. Shlens J, Field GD, Gauthier JL, Grivich MI, Petrusca D, Sher A, Litke AM, Chichilnisky EJ: The structure of multi-neuron firing patterns in primate retina. J Neurosci 2006, 26:8254-8266.
Publish with Bio Med Central and every scientist can read your work free of charge

"BioMed Central will be the most significant development for disseminating the results of biomedical research in our lifetime. "

Sir Paul Nurse, Cancer Research UK

Your research papers will be:

- available free of charge to the entire biomedical community

- peer reviewed and published immediately upon acceptance

- cited in PubMed and archived on PubMed Central

- yours - you keep the copyright

Submit your manuscript here:

http://www.biomedcentral.com/info/publishing_adv.asp 